\title{
A longitudinal study of early childhood caries incidence in Wenzhou preschool children
}

\author{
Xiping Wang, Zhiyuan Wei, Qiao Li and Liqin Mei*
}

\begin{abstract}
Background: Early childhood caries (ECC) is a serious public health problem in China. Few studies, however, have described the incidence of ECC in China. The purpose of this study was to assess the prevalence and incidence of ECC among preschool children in Wenzhou China.

Methods: Preschool children aged 3-4 years old were surveyed and followed up when they reached 5-6 years of age in the city of Wenzhou in southeast China. The rates of dental caries were determined with prevalence, and incidence density for risk of caries of a person $\left(I D_{p}\right)$ and of a tooth surface $\left(I D_{s}\right)$.

Results: The prevalence and decayed, missing, and filled primary teeth (dmft) score of 3-4, 4-5, and 5-6 years old children were $59.8 \%$ and $2.9,71.8 \%$ and 4.2 , and $76.4 \%$ and 4.6 , respectively. The $I D_{p}$ was 29.7 and 14.8 persons/100 person-year during the first and second year. The $\mathrm{ID}_{\mathrm{s}}$ was 5.9 and 2.7 newly affected surfaces/100 surface-year, respectively. The percentage of molars with caries experience increased obviously; the percentage of maxillary central incisors and mandibular incisors with caries experience increased during the first follow-up, whereas it declined during the second follow-up; the others increased gradually.
\end{abstract}

Conclusions: The prevalence and incidence of dental caries in Wenzhou preschool children were very high with most of the carious teeth left untreated. The molars were the most affected teeth during the observation period.

Keywords: Children, Cohort study, Dental caries, Incidence

\section{Background}

Early childhood caries (ECC) is defined as the presence of one or more decayed, missing, or filled surfaces (dmfs) in any primary tooth in children younger than 6 years of age [1]. ECC is a serious public health problem in both developing and developed countries that adversely affects children's overall health [2]. Studies have shown that the major impact of dental caries on children's quality of life were irritation, premature tooth-loss, malnutrition, and delayed growth and development [3].

The prevalence of ECC varies from population to population. Peltzer et al. [4] reported that the prevalence of ECC among 3-year-old children from Northern Thailand was $68.5 \%$. Singh et al. [5] stated that the

\footnotetext{
* Correspondence: wzwlp@sina.com

Department of Preventive and Pediatric Dentistry, School and Hospital of Stomatology, Wenzhou Medical University, Wenzhou 325027, China
}

prevalence of ECC among 717 Indian children(3-5 years old of age) was $40 \%$.

In China, dental caries remains a serious public health problem affecting a large proportion of young children. In China, the Third National Oral Health Survey on dental caries showed a prevalence of $66 \%$ with a mean number of decayed, missing, and filled primary teeth (dmft) of 3.5 in the 5-year-old age group [6].

Most of the previous studies have described the prevalence of ECC at different chronological ages [7-12]. However, few longitudinal studies have described the incidence of ECC in China [13, 14]. Wong et al. [14] stated that the mean caries increment over the 2 years of the children aged 3-4 years old from Hong Kong was 0.9. Ghazal, T., et al. [15] reported that the two-year incidence of ECC among 1-year-old African-American children in Alabama was $39.3 \%$ and the three-year incidence was $65.8 \%$. 
Karjalainen et al. [16] stated that the prevalence of dental caries among 3-year-old Finnish children was 8\%; then it increased to $28 \%$ when they were 6 -year-old. The mean dmft among all children was 0.2 at baseline and 0.9 at the follow-up. Grindefjord et al. [17] assessed the prevalence of ECC among 2.5-year-old Swedish children at baseline (11\%) and 1-year follow-up (37\%). The mean $\mathrm{dmfs}$ increment was 1.9.

A longitudinal study on the progression of dental caries in primary teeth was able to find an appropriate access time for ECC prevention [18]. Hence the knowledge on incidence of ECC will help to develop targeted interventions for prevention of ECC, proper planning for the utilization of scare resource available for oral health prevention program and potential decrease in the prevalence of ECC [19].

Despite these and other published studies, further investigation on the prevalence and incidence of ECC in China was necessary. With no organized dental care available for preschool children in Wenzhou, the present study aimed to investigate the prevalence and the incidence of dental caries in primary teeth with increasing age (e.g., from 3-4 to 5-6 years).

\section{Methods}

\section{Selection of children and sample size}

The study site was located in the city of Wenzhou in southeast China, with three districts included. The per capita gross national product of Wenzhou in 2015 was CNY 36,000, making it a moderately developed region of China. The fluoride concentration in drinking water in this area was around $0.2 \mathrm{mg} / \mathrm{L}$.

A stratified cluster sampling method was used to select the study population. Firstly, the whole geographic area was divided into three districts. Secondly, every district was stratified into developed and developing areas based on the economic income. Thirdly, one kindergarten was selected randomly from the developed and developing areas of different districts, respectively. In the end, in the selected 6 kindergartens, three classes were sampled from Grades 1. The children attending Grades 1 are at least 3 years of age and under 4 years of age. In the 2005 survey, the prevalence of ECC was $66 \%$ in the 5 -year-old age group in China. The sample size estimation showed that the sample size required in this study would be 92 to provide a high precision of the true prevalence with $95 \%$ confidence interval of plus or minus $2 \%$. Because the age of participants was less than 5 years old, it was suspected that the corresponding prevalence of dental caries would be less than $66 \%$. Then, larger sample size was required. Furthermore, in order to improve the precision of the incidence, eventually, 693 children aged 3-4 years were recruited in this study.
During the parents meeting at the beginning of the semester, the aim of this study was explained and the details of the study, including relevant risks, compensation, confidentiality, and contact information, in a printed form were sent to all parents or legal guardians. Written informed consents were obtained from them for the dental health examination on their children. Ethical approval for this study was received from the medical ethics committee of Wenzhou Medical University.

\section{Dental examination and diagnostic criteria}

Dental examination appointments were conducted annually for all eligible subjects by one dentist in the same period of the year for two continuous years.

During the examination, the children were seated on a chair in the classroom. In well-lit premises, the children were examined using a World Health Organization (WHO) probe (no. 621) and a dental mirror under natural light. The outcome variables were the number of $\mathrm{dmft}$ and dmfs. The dmft and dmfs were used by examiners to evaluate dental caries following the WHO criteria [20]. Dental caries was detected by visual inspection without radiography examination. All examinations were conducted by a trained dentist. To assess the intra-examiner reliability, $10 \%$ of the children were reexamined randomly. Kappa statistics was 0.96, 0.98, and 0.96, respectively.

\section{Statistical analysis}

The collected data was entered in Epidata software, version 3.1, and analyzed using SPSS (SPSS, IL, USA). Descriptive statistics was performed. The rates of dental caries were presented as prevalence, crude caries increment and incidence density. The incidence in the present study was calculated as the incidence density for risk of caries of a person $\left(\mathrm{ID}_{\mathrm{p}}\right.$ ) and of a tooth surface $\left(\mathrm{ID}_{\mathrm{s}}\right)$ summarized by formula below [18]:

$$
\begin{aligned}
& \mathrm{ID}_{p}= \frac{\text { Number of new caries }- \text { affected subjects }}{\text { Total person }- \text { time at risk for having }} \\
&\text { at least one caries lesion (person }- \text { year })
\end{aligned}
$$

\section{Results}

A total of 693 children participated in the study. Of these, 87 (12.6\%) children who had participated in dental examination only once were excluded. Consequently, only 606 children were included in the present study. Of these, 269(boys 140, girls 129) were from developing area, and 335(boys 175, girls 160) were from developed area. The mean age of the children was 3.4 years old; 278 (47.9\%) were girls, and 328 (52.1\%) were boys. 606 children accepted dental examination at least twice, of 
which 22 (3.6\%) children attended the first and third examinations. Therefore, the data of 22 children was used only for the prevalence analysis. The remaining 584 (96.4\%) participated in incidence density analysis (Table 1).

ECC was first observed in children at 3-4 years of age. The prevalence of 3-4, 4-5, and 5-6 years old children were $59.8 \%, 71.8 \%$, and $76.4 \%$, respectively. The mean $\mathrm{dmft}$ score of 3-4, 4-5, and 5-6 years old children were 2.9 (standard deviation $[21]=3.7), 4.2(\mathrm{SD}=4.4)$, and 4.6 $(\mathrm{SD}=4.5)$, respectively; the $\mathrm{dmfs}$ scores were $4.9(\mathrm{SD}=$ 9.0), 9.4 $(\mathrm{SD}=12.4)$, and $11.5(\mathrm{SD}=13.7)$, respectively (Table 2). The crude caries increment during the first follow-up was $1.1(\mathrm{SD}=1.7)$, whereas it was $0.7(\mathrm{SD}=$ 1.1) during the second follow-up. The percentage of untreated carious teeth in 5-6-year-old children in this study was $83.6 \%$. The incidence of caries-affected persons $\left(\mathrm{ID}_{\mathrm{p}}\right)$ observed during the first follow-up was 29.7 person/100 person-years, whereas it dropped to 14.8 person/100 person-years during the second follow-up. The rate of new caries-affected tooth surface $\left(\mathrm{ID}_{\mathrm{s}}\right)$ during the first follow-up was 5.9 surfaces/100 surfaceyears, whereas it decreased to 2.7 surfaces/100 surfaceyears during the second follow-up (Table 3).

Figure 1 showed the prevalence of dental caries by tooth type. The percentage of maxillary central incisors with caries experience increased from $39.3 \%$ to $43.3 \%$ during the first follow-up, whereas it declined to $40.9 \%$ during the second follow-up. In maxillary, the percentage of teeth have caries experience increased from $11.9 \%$ to $16.3 \%$ in lateral incisors, $5.4 \%$ to $8.4 \%$ in canines, $13.5 \%$ to $30.0 \%$ in $1^{\text {st }}$ molars and $14.4 \%$ to $36.3 \%$ in $2^{\text {st }}$ molars during the two-year follow-up. The percentage of mandibular incisors with caries experience increased during the first follow-up, whereas it declined during the second follow-up. In mandibular, the percentage of teeth have caries experience increased from $2.7 \%$ to $6.1 \%$ in canines, $24.5 \%$ to $44.8 \%$ in $1^{\text {st }}$ molars and $27.9 \%$ to $45.0 \%$ in $2^{\text {st }}$ molars during the two-year follow-up.

\section{Discussion}

The study found a high prevalence of dental caries at 45 years old of age in Wenzhou, which was higher than the results from the national survey [6]. Wenzhou is a

Table 1 Distribution of children at the time of examination

\begin{tabular}{|c|c|c|c|c|c|}
\hline \multicolumn{3}{|c|}{ Examination time } & \multicolumn{3}{|c|}{ Children attending examination } \\
\hline 2011 & 2012 & 2013 & $\bar{N}$ & $\%$ & Data analysis \\
\hline$\sqrt{ }$ & $\sqrt{ }$ & $\sqrt{ }$ & 377 & 62.2 & Incidence density and prevalence \\
\hline$\sqrt{ }$ & $\sqrt{ }$ & & 46 & 7.6 & Incidence density and prevalence \\
\hline \multirow[t]{3}{*}{$\sqrt{ }$} & & $\sqrt{ }$ & 22 & 3.6 & Prevalence \\
\hline & $\sqrt{ }$ & $\sqrt{ }$ & 161 & 26.6 & Incidence density and prevalence \\
\hline & & Total & 606 & 100.0 & \\
\hline
\end{tabular}

Table 2 Prevalence of dental caries during 2011-2013

\begin{tabular}{llccccr}
\hline Examination time & $\mathrm{N}$ & Age & ECC & Prevalence (\%) & $\mathrm{dmft}$ & $\mathrm{dmfs}$ \\
\hline 2011 & 445 & 3.6 & 266 & 59.8 & 2.9 & 4.9 \\
2012 & 584 & 4.6 & 419 & 71.8 & 4.2 & 9.4 \\
2013 & 560 & 5.6 & 428 & 76.4 & 4.6 & 11.5 \\
\hline
\end{tabular}

moderately developed region in China. With economic development, children have more access to cariogenic sugary food and drinks; however, oral health knowledge, attitudes, and behaviors are lacking. This resulted in a higher prevalence than the national level.

The present study showed that the prevalence of ECC rose sharply from $59.8 \%$ to $71.8 \%$ during the first followup; after that, it increased to $76.4 \%$ during the second follow-up. Meanwhile, the percentage of untreated carious teeth in 5-6-year-old children in this study was $83.6 \%$. The high level of untreated caries could be ascribed to the low pediatric dentist/population ratio in Wenzhou, attitude of parents toward the primary dentition, and high cost of treatment.

Among children unaffected by caries at 3-4 years, $29.7 \%$ were affected during the first follow-up; the children unaffected by caries at $4-5$ years, $14.8 \%$ were affected during the second follow-up. The crude caries increment during the first follow-up period was 1.1; it was 0.7 during the second follow-up period. It showed that the rate of caries increment became lower in the second follow-up. Biologically, this might be due to the higher susceptibility of newly-erupted teeth to dental caries because of the colonization by microorganisms. Weintraub et al. [22] assessed the development of ECC among 126 caries-free children aged 6-44 months at baseline who did not receive fluoride varnish treatment. Including non-cavitated lesions, $29 \%$ had caries incidence after 1-year; at the 2-year follow-up, $24 \%$ of children who were caries-free at 1-year follow-up had caries. The incidence of caries-affected persons $\left(\mathrm{ID}_{\mathrm{p}}\right)$ observed during the first follow-up was 29.7 person/100 person-

Table 3 Frequency, incidence, and rates of risk of caries-affected children/surfaces

\begin{tabular}{lll}
\hline & \multicolumn{2}{l}{ Observation period (years) } \\
\cline { 2 - 3 } & $2011-2012$ & $2012-2013$ \\
\hline$N$ (persons) & 423 & 538 \\
Number of new caries-affected children & 51 & 22 \\
Person-years of observation & 172 & 149 \\
ID $/ 100$ persons at risk & 29.7 & 14.8 \\
$N$ (surfaces) & 35464 & 47344 \\
Number of new caries-affected surface & 1967 & 1130 \\
Surface-years of observation & 33374 & 42309 \\
ID $/ 100$ surface at risk & 5.9 & 2.7 \\
\hline
\end{tabular}




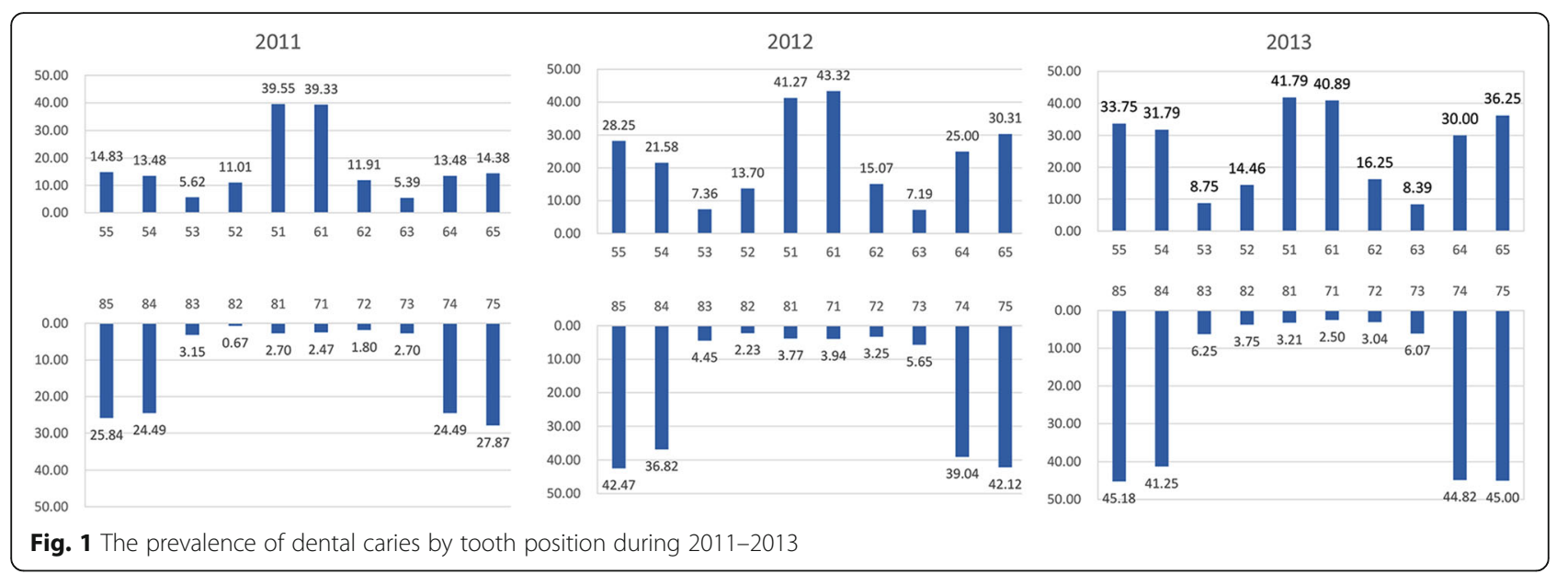

years. Within one year, a rapid destruction of tooth was observed. It is of significant interest and needs further investigation to identify important associated factors in this rapid caries progression. Among previous studies, the factors found to be associated with ECC have included low socioeconomic statue, high consumption of sugar snacks or beverages, poor diet, irregular feeding practices, nutritional problems, poor oral hygiene, and higher levels of Mutans streptococci [13, 23-26].

The analysis of variation in the prevalence of individual tooth revealed that during the follow-up period, the molars were mostly affected, while the incisors had been affected mostly before the survey. During the second follow-up, a little decline was observed in the percentage of carious incisors due to the beginning of mixed dentition. With time, the caries rate of other teeth increased gradually. Previous studies revealed that susceptibility to caries in the study children occurred in the first 3-6 months after the teeth had erupted into the oral cavity [18]. A preventive program must be implemented early in life. Caries affects the maxillary primary incisors and first primary molars in a way that reflects the pattern of eruption [27]. The longer a tooth is exposed to the caries challenge, the more the chances that it will be affected.

Dental caries is a preventable disease, and it can be stopped and even potentially reversed during its early stages. The present study indicated a high caries rate during the follow-up period. If appropriate prevention programs are implemented, the result will be fruitful. A cohort study is suitable for calculating the incidence rate and better characterizing the incremental rate of disease events. The results are easily interpreted. In this study, the incidence of caries-affected persons $\left(\mathrm{ID}_{\mathrm{p}}\right)$ observed during the first 1-year follow-up period was 29.7 person/ 100 person-years, which indicated that if 1000 persons are followed up for 1 year, 297 persons are expected to become carious.
The present study had several limitations. Selected bias was possible. The development of ECC in children younger than 3 years old is unclear. Further investigation is required to identify the risk factors for ECC development. In conclusion, the rate of caries in the study children was extremely high. The molars were the most affected teeth during the observation period, indicating that the access time for ECC prevention should be earlier.

\section{Conclusions}

The prevalence and incidence of dental caries in Wenzhou preschool children were very high with most of the carious teeth left untreated. The molars were the most affected teeth during the observation period.

\section{Bullet points}

Why this paper is important to pediatric dentists

The prevalence of ECC varies from population to population, this study provide the incidence of ECC in China. This paper helps to clearly understand the rate of caries progression of each individual tooth over time to find an appropriate access time for ECC prevention.

\section{Abbreviations}

dmfs: Decayed, missing, and filled surfaces; dmft: Decayed, missing, and filled teeth; ECC: Early childhood caries; SD: Standard deviation; WHO: World Health Organization.

\section{Acknowledgments \\ The authors would like to thank the staff of kindergartens. They would also like to thank the preschool children and their parents for their participation in this study.}

\section{Funding}

The study was supported by Zhejiang province education department project (No.:Y201223271).

\section{Availability of data and materials}

The datasets analyzed during the current study will not be publicly available to protect patient confidentiality. 


\section{Authors' contributions}

XW carried out the studies, collected data, and drafted the manuscript. ZW performed the statistical analysis and participated in its design. QL collected data, performed data analysis and made the charts in the manuscript. LM designed the studies, carried out the dental examination and helped to draft the manuscript. All authors read and approved the final manuscript.

\section{Ethics approval and consent to participate}

This study was approved by the institutional review board of School and Hospital of Stomatology, Wenzhou Medical College and written informed consents were obtained from the parents or legal guardians of participants.

\section{Consent for publication}

Not applicable

\section{Competing interests}

The authors declare that they have no competing interests.

\section{Publisher's Note}

Springer Nature remains neutral with regard to jurisdictional claims in published maps and institutional affiliations.

Received: 3 November 2016 Accepted: 19 June 2017

Published online: 04 July 2017

\section{References}

1. American Academy of Pediatric Dentistry. Policy early childhood caries (ECC): classifications, consequences, and preventive strategies. Pediatr Dent. 2008;30:40-3.

2. Lee GH, McGrath C, Yiu CK, King NM. A comparison of a generic and oral health-specific measure in assessing the impact of early childhood caries on quality of life. Community Dent Oral Epidemiol. 2010;38:333-9.

3. Folayan MO, Kolawole KA, Oziegbe EO, Oyedele T, Oshomoji OV, Chukwumah NM, et al. Prevalence, and early childhood caries risk indicators in preschool children in suburban Nigeria. BMC Oral Health. 2015;15:72.

4. Peltzer K, Mongkolchati A. Severe early childhood caries and social determinants in three-year-old children from Northern Thailand: a birth cohort study. BMC Oral Health. 2015;15:108.

5. Singh S, Vijayakumar N, Priyadarshini HR, Shobha M. Prevalence of early childhood caries among 3-5 year old pre-schoolers in schools of Marathahalli, Bangalore. Dent Res J (Isfahan). 2012;9:710-4.

6. Qi X. Report of the Third National Oral Health Survey in China (in Chinese). China: People's Medical Publishing House; 2008.

7. Li Y, Zhang Y, Yang R, Zhang Q, Zou J, Kang D. Associations of social and behavioural factors with early childhood caries in Xiamen city in China. Int J Paediatr Dent. 2011;21:103-11.

8. King NM, Wu II, Tsai JS. Caries prevalence and distribution, and oral health habits of zero- to four-year-old children in Macau, China. J Dent Child (Chic). 2003:70:243-9.

9. Chu CH, Ho PL, Lo EC. Oral health status and behaviours of preschool children in Hong Kong. BMC Public Health. 2012;12:767.

10. Gao XL, McGrath C, Lin HC. Oral health status of rural-urban migrant children in South China. Int J Paediatr Dent. 2011;21:58-67.

11. Zhang S, Liu J, Lo EC, Chu CH. Dental caries status of Dai preschool children in Yunnan Province, China. BMC Oral Health. 2013:13:68.

12. Zhang S, Liu J, Lo EC, Chu CH. Dental caries status of Bulang preschool children in Southwest China. BMC Oral Health. 2014:14:16.

13. Zhou Y, Yang JY, Lo EC, Lin HC. The contribution of life course determinants to early childhood caries: a 2-year cohort study. Caries Res. 2012:46:87-94.

14. Wong MC, Lu HX, Lo EC. Caries increment over 2 years in preschool children: a life course approach. Int J Paediatr Dent. 2012;22:77-84.

15. Ghazal T, Levy SM, Childers NK, Broffitt B, Cutter G, Wiener HW, et al. Prevalence and incidence of early childhood caries among AfricanAmerican children in Alabama. J Public Health Dent. 2015;75:42-8.

16. Karjalainen S, Soderling E, Sewon L, Lapinleimu H, Simell O. A prospective study on sucrose consumption, visible plaque and caries in children from 3 to 6 years of age. Community Dent Oral Epidemiol. 2001;29:136-42.

17. Grindefjord M, Dahllof G, Modeer T. Caries development in children from 2. 5 to 3.5 years of age: a longitudinal study. Caries Res. 1995;29:449-54.

18. Thitasomakul S, Thearmontree A, Piwat S, Chankanka O, Pithpornchaiyakul W, Teanpaisan R, et al. A longitudinal study of early childhood caries in
9- to 18-month-old Thai infants. Community Dent Oral Epidemiol. 2006;34:429-36.

19. Olatosi OO, Inem V, Sofola OO, Prakash P, Sote EO. The prevalence of early childhood caries and its associated risk factors among preschool children referred to a tertiary care institution. Niger J Clin Pract. 2015;18:493-501.

20. World Health Organization. Oral health surveys: basic methods. 3rd ed. Geneva: WHO; 1987.

21. Vij S, Kuhl H, Kuznetsova IS, Komissarov A, Yurchenko AA, Van Heusden P, et al. Correction: Chromosomal-Level Assembly of the Asian Seabass Genome Using Long Sequence Reads and Multi-layered Scaffolding. PLoS Genet. 2016:12:e1006500.

22. Weintraub JA, Ramos-Gomez F, Jue B, Shain S, Hoover Cl, Featherstone JD et al. Fluoride varnish efficacy in preventing early childhood caries. J Dent Res. 2006;85:172-6.

23. Warren JJ, Weber-Gasparoni K, Marshall TA, Drake DR, Dehkordi-Vakil F, Kolker $J$, et al. Factors associated with dental caries experience in 1-yearold children. J Public Health Dent. 2008:68:70-5.

24. Warren JJ, Weber-Gasparoni K, Marshall TA, Drake DR, Dehkordi-Vakil F, Dawson DV, et al. A longitudinal study of dental caries risk among very young low SES children. Community Dent Oral Epidemiol. 2009;37:116-22.

25. Thitasomakul S, Piwat S, Thearmontree A, Chankanka O, Pithpornchaiyakul W, Madyusoh S. Risks for early childhood caries analyzed by negative binomial models. J Dent Res. 2009;88:137-41.

26. Palmer CA, Kent Jr R, Loo CY, Hughes CV, Stutius E, Pradhan N, et al. Diet and caries-associated bacteria in severe early childhood caries. J Dent Res. 2010;89:1224-9.

27. Kawashita Y, Kitamura M, Saito T. Early childhood caries. Int J Dent. 2011; 2011:725320.

\section{Submit your next manuscript to BioMed Central and we will help you at every step:}

- We accept pre-submission inquiries

- Our selector tool helps you to find the most relevant journal

- We provide round the clock customer support

- Convenient online submission

- Thorough peer review

- Inclusion in PubMed and all major indexing services

- Maximum visibility for your research

Submit your manuscript at www.biomedcentral.com/submit

) Biomed Central 